\title{
Sight Spot Buffer Model Based on Tourists’ Interests
}

\author{
Xiao Zhou*, Shun He, Shixiang Zhang, Wei Chen, Yu Chen and Youwei Ma \\ Information Engineering University, No.62 Kexue Avenue, High-tech Zone, Zhengzhou, China \\ ${ }^{*}$ Corresponding author
}

\begin{abstract}
Aim at the current problems that tourism GIS cannot provide individual service to meet the needs of tourists, this paper brings forward sight spot buffer model based on tourists' interests and needs. Firstly, sight spot classification model is set up and all the sight spots are coded. According to tourists' needs, sight spot interest needs model is set up. Aim at specific needs, interest sight spot buffer model is set up and sight spot as well as service information around within the buffer is classified. Sight spot buffer maps in the sample example proves that this model can help tourists to rapidly know sight spots and service information around, which can provide tourism decision support and increase efficiency.
\end{abstract}

Keywords-Interest needs; sight spot; sight spot buffer; classification information

\section{INTRODUCTION}

Before tourists going to visit an unfamiliar city, they usually study the sight spots in the city and plan the proper route. According to the sight spot star and public comments, they mainly choose proper and interested ones to have a tour. Tourists usually get tourism information by purchasing books in the store, surfing Internet, turning to travel agency, etc., which is passive. The analysis and selecting on sight spots is subjective. As to current tourism GIS, they mainly provide sight spots' mass geographic information, which considers no individual needs and interests and cannot provide special service for single individuality. According to the age, tourists can be divided into several grades. Each grade has different needs and interests, and developing one kind of tourism GIS cannot meet the needs of all grades. In the mean time, mixing all kinds of service information and GIS information cannot provide individual service. Aim at these problems, based on the current tourism GIS, this paper brings forward sight spot buffer model based on tourists' interests and needs. This model can provide sight spot information and service information around within buffer relying on tourists' needs and interests, which can provide convenience for tourists to select sight spots and plan tour route.

\section{TOURIST INTEREST NEEDS MODEL}

\section{A. Sight Spot Classification Model}

Take Zhengzhou city for example. According to sight spot features, sight spots in Zhengzhou city can be classified into four sorts $S_{i}, i \in(0,4] \in \mathrm{Z}^{+}$. Sort $S_{1}$ : Park and Greenland. Sort $S_{2}$ : Shopping. Sort $S_{3}$ : Venue. Sort $S_{4}$ : Entertainment.
In each sight spot sort, several sub-sorts are set as $S_{i} R_{j}$, $j \in\left(0, \max k_{i}\right] \in \mathrm{Z}^{+} . k_{i}$ is the maximum sight spot number of a certain sort. TABLE I is the sight spots of each sort. Take sight spots as elements to set up sight spot classification database and store sight spot codes, as FIGURE I shows.

\section{TABLE I. SIGHT SPOT CLASSIFICATION AND ELEMENTS}

\begin{tabular}{|c|c|c|c|}
\hline $\begin{array}{c}\text { Sight } \\
\text { spot }\end{array}$ & Sight spot code & $\begin{array}{c}\text { Sight } \\
\text { spot }\end{array}$ & Sight spot code \\
\hline \multirow{5}{*}{$S_{1}$} & $S_{1} R_{1}$ Renmin Park & & $S_{3} R_{1}$ HenanMuseum \\
& $S_{1} R_{2}$ Bishagang Park & & $S_{3} R_{2}$ GeologyMuseum \\
& $S_{1} R_{3}$ Zijingshan Park & & $S_{3} R_{3}$ ErqiMuseum \\
& $S_{1} R_{4}$ Forest Park & \multirow{2}{*}{$S_{3}$} & $S_{3} R_{4}$ Gallery \\
& $S_{1} R_{5}$ Lvcheng Square & & $S_{3} R_{5}$ ZhengzhouMuseum \\
& $S_{1} R_{6}$ Botanical garden & & $S_{3} R_{6}$ Science museum \\
& $S_{1} R_{7}$ Zhengzhou zoo & & $S_{3} R_{7}$ Aquarium \\
& $S_{1} R_{8}$ YellowRiver View & & \\
\hline \multirow{5}{*}{$S_{2}$} & $S_{2} R_{1}$ Wangfujing & & $S_{4} R_{1}$ CenturyPark \\
& $S_{2} R_{2}$ Department store & & $S_{4} R_{2}$ FountPark \\
& $S_{2} R_{3}$ Erqi Uanda & \multirow{2}{*}{$S_{4}$} & $S_{4} R_{3}$ WaterPark \\
& $S_{2} R_{4}$ Zhongyuan Unada & & $S_{4} R_{4}$ ChildrenPark \\
& $S_{2} R_{5}$ Dehua street & & \\
\hline & $S_{2} R_{6}$ CC mall & & \\
\hline
\end{tabular}

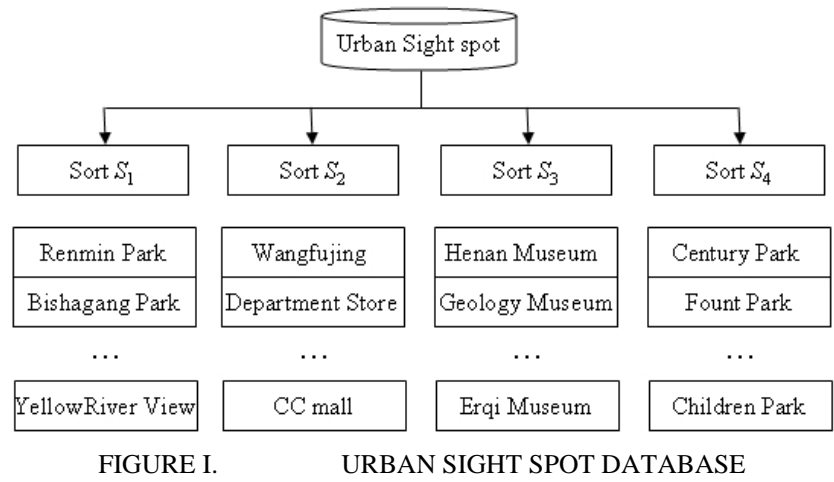

\section{B. Interest Needs Model}

According to the provided sight spots in the tourism GIS, tourists choose sight spots in two ways. One is selecting directly, the other is selecting randomly. 
Method 1 Selecting directly. Under the condition of tourists being familiar with sight spots and having certain needs or interests on sight spots, they can directly load in selecting interface and select the interested sight spots in each sort, as FIGURE II shows.

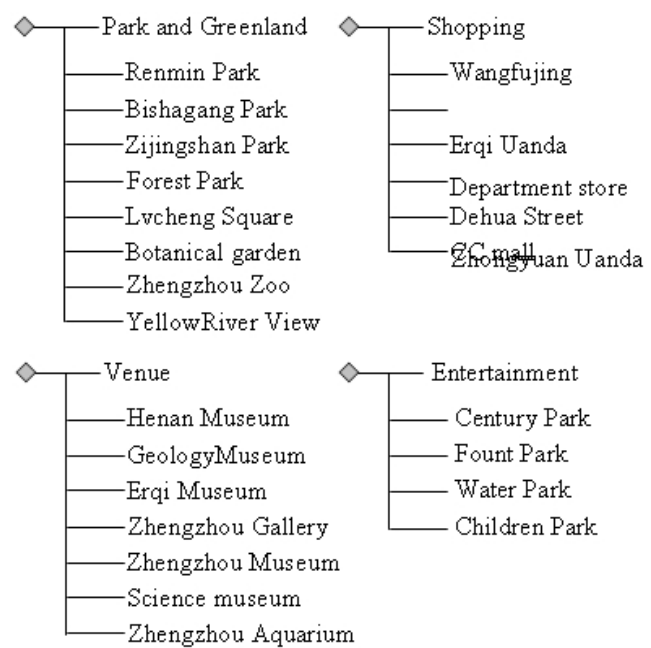

FIGURE II. SIGHT SPOT SELECTING IN THE SYSTEM

Method 2 Selecting randomly. When tourists are not familiar with the sight spots, they can turn to the system for help. Firstly, tourists provide the number of sight spots, and then system transfers random function to generate random numbers. Set the distribution function of continuous random variable $X$ as:

$$
F(x)=\frac{x-a}{b-a}, x \in[a, b]
$$

Continuous random variable $X$ meets the uniform distribution on $[a, b]$, note as $X \sim U(a, b)$. Transfer uniform distribution function for one time on $[a, b]$ can get random numbers within the maximum value $b$. Select the uniform distribution function on $[0, k]$ to set up sight spot element random selecting model, in which $k$ is the maximum sight spot number of one sight spot sort.

\section{INTEREST Sight SPOT BUfFER MODEL}

Buffer area is the obtained object neighborhood after the confirmation of the object, whose range is determined by neighborhood radius or buffer foundation conditions. Thus, as to a certain object $K_{t}$, its buffer area is defined as follows.

$$
P=\left\{x \mid d\left(x, K_{t}\right) \leq r\right\}
$$

The object $K_{t}$ buffer area with neighborhood radius $r$ is the collection of points whose distance $d$ to object $K_{t}$ are less than $r$. Index $d$ can be minimum Euclidean distance or other defined distance.

Set the sight spot as center to set up buffer model. Set the buffer radiuses are $(\mathrm{km})$ :

- $r_{1}=0.5$

- $\quad r_{2}=1.0$

- $r_{3}=1.5$

- $r_{4}=2.0$.

Draw sight spot service information within four radiuses respectively, including $\lambda_{1}$ sight spot star, $\lambda_{2}$ bus station number, $\lambda_{3}$ subway station number, $\lambda_{4}$ hotel number, $\lambda_{5}$ shop number and $\lambda_{6}$ bank number. Take entertainment for example, Table II is sight spot service information and indexes within four radiuses.

\section{TABLE II. SIGHT SPOT SERVICE INFORMATION AND} INDEXES $\lambda_{1} \sim \lambda_{6}$

\begin{tabular}{|c|c|c|c|c|}
\hline Sight spot & $r_{1}=0.5$ & $r_{2}=1.0$ & $r_{3}=1.5$ & $r_{4}=2.0$ \\
\hline D1Century Park & $4,2,0,1,2,3$ & $4,3,0,2,3,3$ & $4,3,0,3,5,3$ & $4,4,1,4,5,4$ \\
\hline D2 Fount Park & $5,1,0,0,2,0$ & $5,2,0,0,1,0$ & $5,3,0,0,2,1$ & $5,4,0,1,3,1$ \\
\hline D3 Water World & $3,2,0,3,3,2$ & $3,2,1,5,3,4$ & $3,3,1,5,5,4$ & $3,3,1,5,5,4$ \\
\hline D4 Children Park & $2,2,1,2,4,3$ & $2,2,1,4,5,4$ & $2,3,1,4,6,4$ & $2,3,1,5,6,4$ \\
\hline
\end{tabular}

As to multi-level sight spot information, tourists can choose a certain level, such as bus station. Look up the name of bus station, location, bus number, time information and transfer information, etc. All the information is close to the sight spots, so it is critical for tourists to select sight spots and seize sight spot information, and it is important condition for tourists to meet the best motive benefits. After selecting sight spots, tourists can get sight spot buffer and information on the map.

\section{MODEL EXAMPLE}

Model example is designed according to the model set up. A tourist requires visiting one Park and Greenland, one shopping mall and one venue. He is unfamiliar with Zhengzhou city and turns to system for help. System invokes distribution function to generate random numbers according to tourists' needs and draws one Park and Greenland, one shopping mall and one venue. TABLE III is the sight spot service information indexes within the three sight spot buffer.

TABLE III. SIGHT SPOT SERVICE INFORMATION AND INDEXES

$$
\lambda_{1} \sim \lambda_{6}
$$

\begin{tabular}{|c|c|c|c|c|}
\hline Sight spot & $r_{1}=0.5$ & $r_{2}=1.0$ & $r_{3}=1.5$ & $r_{4}=2.0$ \\
\hline A2 Bishagang Park & $3,4,1,3,4,3$ & $3,4,1,4,4,4$ & $3,5,2,4,4,5$ & $3,5,2,5,5,6$ \\
\hline B6 CC mall & $3,2,1,2,3,2$ & $3,2,1,2,4,3$ & $3,3,2,3,5,4$ & $3,3,2,4,6,5$ \\
\hline $\begin{array}{c}\text { C5 Zhengzhou } \\
\text { Museum }\end{array}$ & $4,4,1,3,3,2$ & $4,5,1,4,5,3$ & $4,5,1,5,6,3$ & $4,5,1,6,7,4$ \\
\hline
\end{tabular}


According to the selected sight spots and different service information within buffer, interest sight spot buffer model is set up on the tourism map, as FIGURE III shows.

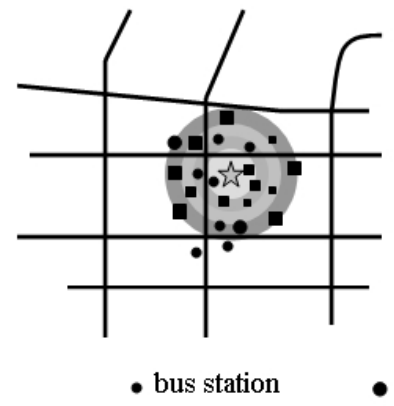

FIGURE III.

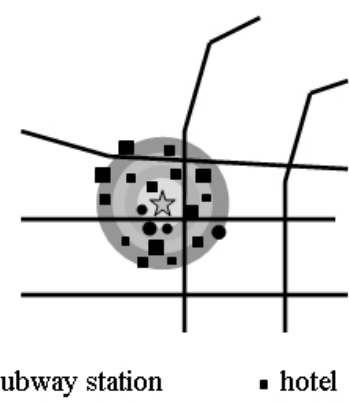

SIGHT SPOT BUFFER INFORMATION MAPS
This model realizes the function of displaying interest sight spot and service information within buffer via different levels in mass data, which has relatively high pertinence. As to all the sight spot service information within buffer, it includes all the information tourists demand. The distribution location, service information integrity and convenience extent all meet the basic needs. Tourists can get best motive benefits by visiting the selected sight spots. Through the interest sight spot buffer service function in the tourism GIS, tourists can choose sight spots, look up information in different levels and know the sight spots rapidly to make a proper decision, which can raise the tourism efficiency.

\section{CONCLUSION}

Aim at the problems of current tourism GIS being lack of individuality service which can not meet tourists' interests and needs, this paper brings forward sight spot buffer model based on tourists' interests and needs. Through the interest sight spot buffer service function in the tourism GIS, tourists can choose sight spots, look up information in different levels and know the sight spots rapidly to make a proper decision, which can raise the tourism efficiency.

\section{REFERENCES}

[1] Nicolau J L, Ma' s F J. The influence of distance and prices on the choice of tourist destinations: the moderating role of motivations [J]. Tourism Management, 2006, 27: 982-996.

[2] ZHAO X M, SUN Q X, DING Y. Passenger choice behavior for regional rail transit under express/local operation with overtaking[J]. Journal of Transportation Systems Engineering and Information Technology, 2016, 16(5): 104-109.

[3] ZHAO X, GUAN H Z, WANG H. An analysis on choice behavior of tourist destination based on tourist motivation[J]. Journal of Transportation Systems Engineering and Information Technology, 2014, 14(5): 175-180.

[4] LI X J, CUI S S, ZHANG K. Neural net method of best tourism route choice[J]. Transportation and Computer, 2006, 24(5): 103-106.

[5] XU F, DU J P. Study on travel route planning based on improved ant colony algorithm[J]. Computer Engineering and Applications, 2009, 45(23): 193-195.

[6] Nicolau J L, Ma's F J, Sequential choice behavior: Going on vacation and type of destination[J]. Tourism Management, 2008, 29:1023-1034.

[7] LONG X Q, WANG J J, ZHOU B. Travelers dynamic decision making based on decision field theory[J]. Journal of Transportation Systems Engineering and Information Technology, 2016, 16(1): 12-18.
[8] Bosque I R, Martin H S. Tourist satisfaction: A cognitive affective model [J]. Annals of Tourism Research, 2008, 35( 2) : 551-573.

[9] WANG C Y, QU H L. Tourist motive, destination image and tourism expectation[J]. Tourism Tribune, 2013, 28(6): 26-34.

[10] LI M, CAI L A. The effects of personal values on travel motivation and behavioral intention[J]. Journal of Travel Research, 2011, 51( 4) :473487. 